\title{
ENSEÑANZA DEL PROCESAMIENTO DIGITAL DE IMÁGENES A TRAVÉS DE OBJETOS VIRTUALES DE APRENDIZAJE EN ENTORNOS E-LEARNING
}

\section{TEACHING DIGITAL IMAGE PROCESSING THROUGH VIRTUAL LEARNING OBJECTS IN E-LEARNING ENVIRONMENTS}

\author{
Ing. Marjorie Jácome*, PhD. Cesar Torres, PhD. Carmen Araujo* \\ "Laboratorio de óptica e Informática LOI-Universidad Popular del Cesar. \\ Sede Hurtado, Valledupar, Cesar, Colombia. \\ E-mail: \{jmjacome, Cesartorres, Carmenaraujo\}@unicesar.edu.co
}

\begin{abstract}
Resumen: La presente investigación permite el diseño, estructuración y ejecución de un curso virtual, en metodología autodidacta en la plataforma Moodle, el cual se comporta como una atmósfera para la generación de una cultura de aprendizaje autónomo, recursividad, actualización e innovación en la comunidad académica, empleando herramientas multimedia como imágenes, audio, video, objetos virtuales de aprendizaje, objetos informativos como gráficos, infografías, objetos de aprendizaje como simuladores, juegos, contenido instruccional, tutoriales.
\end{abstract}

Palabras clave: Enseñanza, e-Learning, Objeto Virtual de Aprendizaje, Procesamiento Digital de Imágenes.

\begin{abstract}
This research led to the design, structuring and implementation of a virtual course in self methodology in the Moodle platform, which behaves like an atmosphere for generating a culture of autonomous learning, resourcefulness, updating and innovation in the academic community, using multimedia tools such as images, audio, video, virtual learning objects, information objects such as graphics, infographics, learning objects as simulators, games, instructional content, tutorials.
\end{abstract}

Keywords: Education, e-Learning, Virtual Learning Object, Digital Image Processing.

\section{INTRODUCCIÓN}

El procesado digital de imágenes PDI puede definirse como un conjunto de procedimientos que se realizan sobre una imagen, para su almacenamiento, transmisión o tratamiento. El PDI es una rama de la ingeniería de software nacida a partir de la unión y avance de las

matemáticas con los computadores digitales. A raíz de esto, se empieza a usar el PDI en otras áreas interdisciplinares como la informática, ciencias básicas, ingeniería, biología, radiología, patología, geología, meteorología, oncología, entre otros (Morales, 2012).
En cuanto a la educación el PDI es enseñado a los estudiantes de ingeniería/ciencias, desarrolladores de software, y científicos en ejercicio; por consiguiente, este tema de investigación se encaminó a la determinación de estrategias pedagógicas y didácticas articuladas con las TIC para la enseñanza del PDI a través de OVAs en entornos e-Learning.

Se aplicó una encuesta online a una muestra de 40 docentes de la Maestría en Ciencias Físicas del SUE Caribe (Sistema de Universidades Estatales del Caribe Colombiano) elaborada en Google Docs, en la que se consiguió analizar las estrategias pedagógicas y didácticas usadas en la enseñanza 
del PDI; así mismo, las principales dificultades que presentan los estudiantes y docentes en el proceso de aprendizaje/enseñanza respectivamente, entre las cuales prevalecieron las falencias en la lógica de programación, desconocimiento de conceptos de algebra matricial y poca comprensión del análisis matemático.

La enseñanza del tratamiento digital de imágenes se ha posicionado en las ciencias en los últimos años, de hecho, ha sido incluida en los pensum de las nuevas titulaciones universitarias de ingeniería. Uno de los problemas que se presentan a la hora de impartir dichas enseñanzas es la falta de laboratorios estructurados para aprender y poner en práctica los conocimientos adquiridos en las clases de teoría.

Esto se debe, en su mayor parte, al elevado precio de las tarjetas de procesado digital de imágenes, siendo difícil disponer de un laboratorio con un número suficiente de puestos de trabajo. Afortunadamente, hoy en día, la mayor parte de los alumnos tienen ordenador propio y los laboratorios disponen de suficientes puestos con ordenador (Barea et al., 2008). Por tanto, se hacen evidentes los beneficios de disponer de un curso autodidacta sobre el aprendizaje del PDI a través de OVAs en entornos e-Learning, que a través de herramientas multimedia como imágenes, audio, video, objetos virtuales de aprendizaje, objetos informativos como gráficos, infografías, objetos de aprendizaje como simuladores, juegos, contenido instruccional, tutoriales.), entre otros, se facilite la comprensión teórica practica de esta temática. Con la elaboración de este curso se busca que, de manera autónoma, el estudiante aprenda no solo los principios y las herramientas utilizadas para procesar imágenes, sino también la forma de emplearlos en la solución de problemas prácticos.

\section{AMBIENTES VIRTUALES DE APRENDIZAJE: MOODLE Y EXELEARNING}

La capacidad de generar conocimiento de manera autónoma, se ha transformado en un reto para sobrevivir y avanzar en el diario vivir. El aprendizaje autónomo es la capacidad que tiene una persona de tomar sus propias decisiones en pro de construir su propio aprendizaje teniendo presente el contexto, metas, condiciones, necesidades y objetivos pro-puestos.

Las tecnologías de la información y la comunicación (TIC) han transformado los procesos de aprendizaje enseñanza, se han convertido en un lenguaje universal, facilitando por medio de herramientas la transmisión de información para generar aprendizaje que se transforma en conocimiento. Por tal motivo, es sumamente importante formar competencias digitales en todos los ciudadanos, estudiantes y docentes.

Los ambientes virtuales de aprendizaje (UNAD, 2015) son una oportunidad de formación para aquellas personas que quieren innovar en la búsqueda del conocimiento, que buscan una nueva posibilidad para la profesionalización o formación permanente, así como para quienes desean mejorar sus competencias con el propósito de desempeñarse de acuerdo a las tendencias o necesidades específicas. Con la inclusión de las TIC, la educación se transforma internamente para impactar el mundo externo; es tanto el alcance que los roles que participan en un entorno educativo se han tenido que redefinir. A partir del cambio que sufren los actores en la educación, se ha desencadenado un nuevo modelo educativo centrado en el estudiante, donde el docente pasa a cumplir la función de facilitador, mentor, guía, y en el que el estudiante entra a conocer como generar su propio aprendizaje de manera autónoma, interactuando con el medio, colaborativamente con sus compañeros y tutor, construyendo su aprendizaje en base a conocimientos previos (aprendizaje significativo) adentrándose así a la nueva era de la educación empleando entornos virtuales de aprendizaje.

Los entornos virtuales de aprendizaje pueden describirse como un espacio en el que estudiantes y docentes interactúan generando aprendizaje. El ambiente virtual de aprendizaje es un espacio que promueve las relaciones e interacción de conocimiento usando herramientas tecnológicas.

Existen varias plataformas que soportan estos tipos de modelos educativos, los WebCT, Moodle, Atutor, Blackboard, claroline, Dokeos, ecollege, Desire2learn, son plataformas LMS (Sistema de Gestión de Aprendizaje) que facilitan la gestión de sistemas educativos, permiten la inclusión de contenidos educativos digitales para ofertar de manera virtual aprendizaje a sus aprendices.

Bajo el enfoque constructivista, para el presente proyecto se eligió Moodle, plataforma de aprendizaje diseñada para proporcionarles a educadores, administradores y estudiantes un sistema integrado único, robusto y seguro para crear ambientes de aprendizaje personalizados. La 
pedagogía es el arte o ciencia de instruir a otros. El fuerte de Moodle es la posibilidad de ofertar cursos conformados por actividades y recursos. Moodle ofrece veinte opciones diferentes para generar actividades en los cursos virtuales implementados. Es posible incluir foros, lecciones, glosarios, talleres, wikis, tareas, quiz, encuestas, SCORM, bases de datos, y personalizarlas de acuerdo a la necesidad. Usar estas herramientas y combinarlas, ayuda al tutor a guiar al estudiante de manera didáctica y creativa a la generación de aprendizaje propio y de valor.

Así, cada actividad se puede construir basándose sobre los resultados de las actividades previas. Moodle cuenta con Phet, un sitio para las simulaciones interactivas para la ciencia (física, biología, química, ciencias de la Tierra) y matemáticas en primaria, secundaria, bachillerato y niveles universitarios, de la Universidad de Colorado en Boulder, EE.UU., que ofrece diversión, libre, interactivo, ciencias y simulaciones matemáticas basadas en la investigación. Las simulaciones están escritos en Java, flash o HTML5, y se pueden ejecutar en línea o descargar al servidor Moodle en el ordenador.

Todas las simulaciones son de código abierto. Es importante destacar que al igual que el producto de esta investigación, el diseño y desarrollo de Moodle se guía por una pedagogía constructivista. Desde este punto de vista, la gente activamente construye nuevos conocimientos a medida que interactúan con sus entornos.

\section{ANÁLISIS DE RESULTADOS}

\subsection{Análisis encuestas}

A partir de la encuesta online aplicada a una muestra de 40 docentes de la Maestría en Ciencias Físicas del SUE Caribe (Sistema de Universidades Estatales del Caribe Colombiano) elaborada en Google Docs, se obtuvieron los siguientes resultados como análisis cualitativo:

Según la Figura1 entre las estrategias didácticas más usadas en la enseñanza del PDI, en su respectivo orden de mayor a menor, se encuentran: exposiciones, investigaciones, proyectos y talleres colaborativos, lo que demuestra que aún en materias altamente tecnológicas de pregrado se imparten las clases magistralmente (Entonado y Díaz, 2009). El profesor del siglo XXI se encuentra ante un particular desafío, ya sea como profesor presencial que utiliza las TIC en clase, o como eformador o e- tutor de enseñanza abierta y a distancia, pues tiene que actualizar sus conocimientos para poder hacer un uso adecuado de estas herramientas. El e-learning, supondrá un cambio positivo en el rol del profesor. Las responsabilidades y principios básicos de la educación tradicional parecen, en principio, fácilmente extensibles a un contexto de e-learning, ya que son complejas y presentan múltiples dimensiones en cualquier contexto. Por consiguiente, con esta investigación se pretende emplear las TIC para implementar nuevas didácticas para la enseñanza del PDI.

La incorporación de las TIC como mediadoras del proceso de aprendizaje nos lleva a valorar y a reflexionar sobre su eficacia en la enseñanza. La didáctica se ha constituido como el ámbito de organización de las reglas para hacer que la enseñanza sea eficaz. Quizás sea ésa una de las razones de asimilación con el "cómo" de la enseñanza, cuestión que ha llevado al solapamiento de ésta con la cuestión metodológica, un aspecto de la didáctica que ha sido escasamente abordado en los últimos años (Fandos et al., 2002).

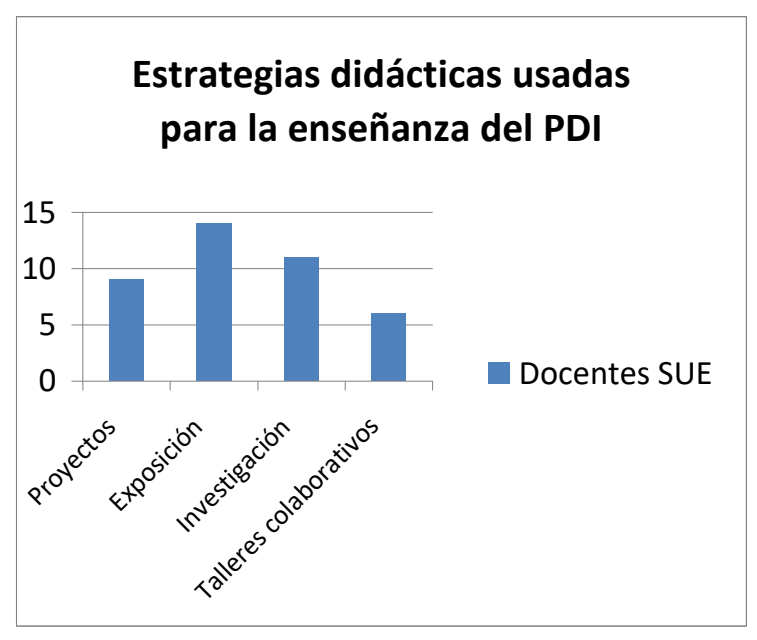

Fig. 1. Estrategias didácticas usadas para la enseñanza del PDI según muestra de 40 docentes del SUE Caribe

En la Figura 2 se observa que entre las dificultades que presentan los estudiantes en el proceso de aprendizaje del PDI, en su orden de mayor a menor, se encuentran: la comprensión del álgebra lineal/matricial, las falencias en la lógica de programación, dificultades en el análisis matemático y desconocimiento de lenguajes de programación. No solo se necesita dominar un lenguaje de programación, sino ante todo contar con el dominio de la lógica que este requiere. El PDI se ha trabajado desde dos enfoques; uno desde 
el punto de vista del procesamiento digital de señales, en el cual se trabaja en el dominio de las frecuencias con ayuda de la transformada de Fourier. El otro en el dominio espacial donde se considera la imagen digital como una matriz, en este enfoque el procesamiento se realiza utilizando álgebra matricial. MATLAB es un sistema de trabajo interactivo cuyo elemento son las matrices.

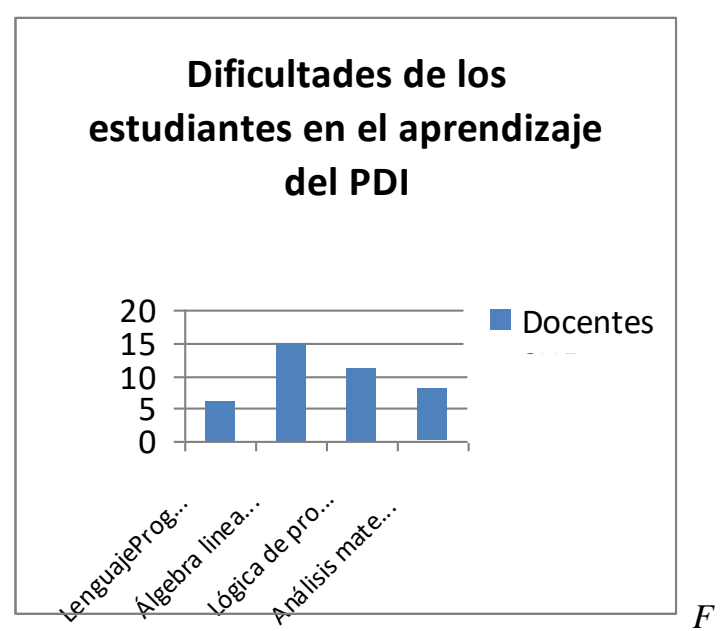

ig. 2. Dificultades de los estudiantes en el aprendizaje del PDI según muestra de 40 docentes del SUE Caribe

En el procesamiento de señales e imágenes se utilizan algunas técnicas sustentadas en el conocimiento de los operadores lineales y no lineales. El avance de las tecnologías de comunicación e información permiten hoy en día la aplicación de imágenes (matrices) y transformaciones del álgebra lineal a diversas áreas de las ciencias puras y aplicadas así como de la ingeniería. Los conceptos de espacio vectorial y algebra lineal resultan ser muy naturales en el procesamiento de señales. Y más aun en el procesamiento de imágenes digitales, ya que una imagen digital es una matriz. Las operaciones matriciales juegan un papel importante en el PDI.

En cuanto a las dificultades que enfrentan los docentes en la enseñanza del PDI, Figura 3, se observa la ausencia de laboratorios bien dotados con la tecnología necesaria para que los estudiantes puedan realizar sus prácticas.

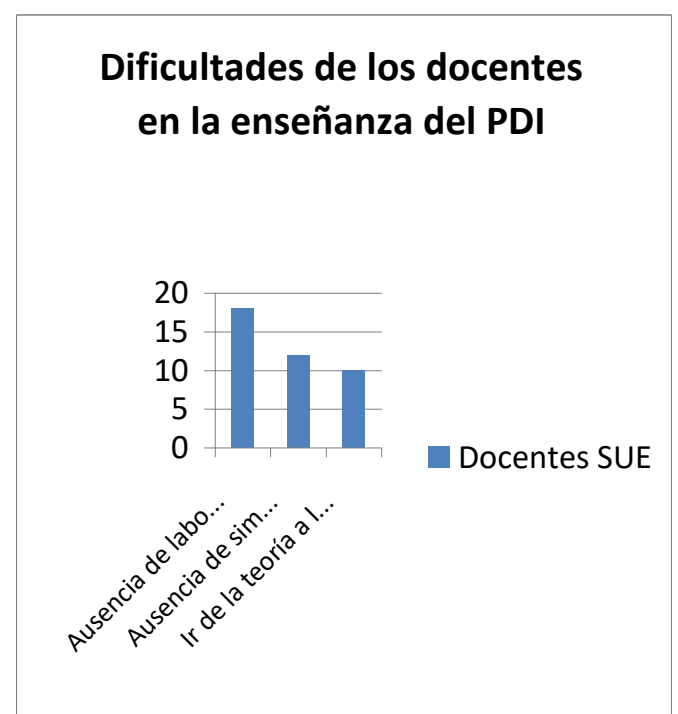

Fig. 3. Dificultades de los docentes en la enseñanza del PDI según muestra de 40 docentes del SUE Caribe

Lo anterior se presenta debido al alto precio de las tarjetas de procesado digital de imágenes, lo que imposibilita disponer de un laboratorio con suficientes equipos. El presente curso solventará el problema de laboratorios físicos por medio de laboratorios simulados.

\subsection{Análisis curso implementado}

Se fabricó un curso interactivo para el aprendizaje de conceptos y algoritmos del PDI. La principal función de este sistema es proveer a potenciales usuarios de una herramienta eficiente para ayudar en la comprensión de conocimientos básicos en el campo del procesamiento de imágenes.

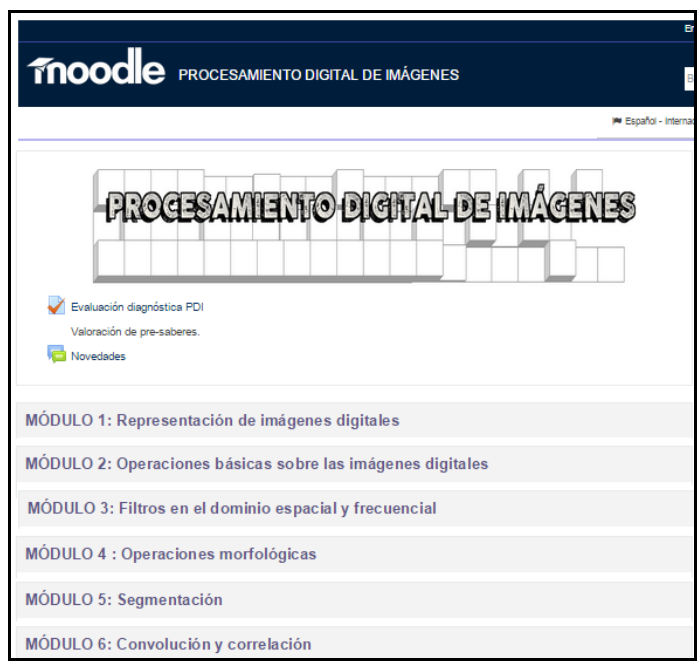

Fig. 4. Página principal curso PDI en plataforma Moodle.

Fuente: http://localhost/course/view.php?id=2\#section-1 


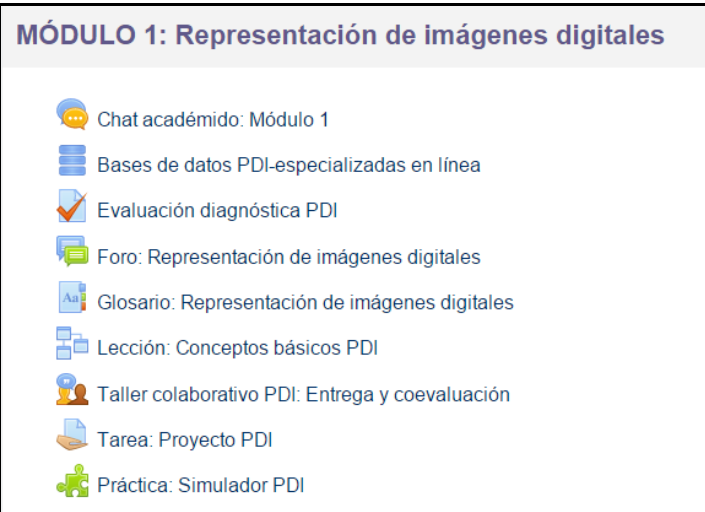

Fig. 5. Ejemplo contenido módulo 1.

Fuente: http://localhost/course/view.php?id=2\#section-1

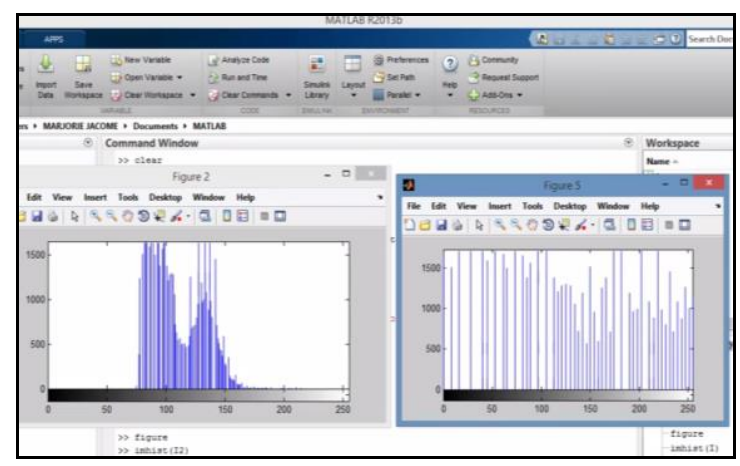

Fig. 6. Simulador histogramas

Fuente: http://localhost/course/view.php?id=2\#section-128

\section{CONCLUSIONES}

A partir del análisis de los resultados arrojados en la encuesta, se construyó un curso autodidacta en modalidad E-Learning para la enseñanza del PDI a través de OVAs, con el cual se pretende proporcionar una cimentación matemática y algorítmica para comprender las diferentes técnicas de procesamiento y análisis de imágenes digitales. Este curso está diseñado para que de forma autónoma el estudiante conozca, entienda y aplique las técnicas fundamentales usadas en el PDI y reconocimiento de patrones, para resolver problemas reales de interés práctico y familiarizarse con algunas de las herramientas computacionales más utilizadas en la actualidad.

\section{REFERENCIAS}

R. R. Morales and J. H. S. Azuela (2012), Procesamiento y Análisis Digital de Imágenes, Primera Ed. México D.F.: Alfaomega Grupo Editor, S.A. de C.V.

R. Barea, L. Boquete, L. M. Bergasa, and M. Mazo (2008), "Un Programa Interactivo para la Enseñanza de Algoritmos de Procesamiento Digital de Imágenes," Form. Univ., vol. 1, no. 5, pp. 341-346.

U. A. Velasquez, J.G, (2006), "Herramienta de Apoyo para Cursos de Procesamiento Digital de Imagen," pp. 1-15.

F. B. Entonado and L. Díaz (2009), "Funciones del Profesor De E-Learning," ChPixel-Bit. Rev. Medios y Educ., pp. 205 - 215.

M. Fandos, J. Jiménez, and G. Angel (2002), "Estrategias didácticas en el uso de las TIC," Acción Pedagógica, vol. 11, no. Acción Pedagógica, p. págs 28-39.

\section{SITIOS WEB}

"UNIDAD 3: Aprendizaje en ambientes virtuales." [Online]. Available: http://datateca.unad.edu.co/contenidos/434206/ 434206/unidad_3_aprendizaje_en_ambientes_v irtuales.html. (31-Jul-2015)

"Pedagogía - MoodleDocs." [Online]. Available: https://docs.moodle.org/all/es/Pedagog\%C3\%A Da. ( 31-Jul-2015)

"Simulaciones Phet - MoodleDocs." [Online]. Available:https://docs.moodle.org/29/en/PhET_ simulations. ( 31-Jul-2015)

"Filosofía - MoodleDocs." [Online]. Available: https://docs.moodle.org/29/en/Philosophy. (31Jul-2015)

"Página oficial del curso Fundamentos de Proesamiento de Imágenes." [Online]. Available: http://dmery.ing.puc.cl/index.php/teaching/ima genes/. [Accessed: 30-Jul-2015]. 